\section{Germination and Emergence of Parsley in Response to Osmotic or Matric Seed Priming and Treatment with Gibberellin}

\author{
Wallace G. Pill ${ }^{1}$ and Elizabeth A. Kilian ${ }^{2}$ \\ Department of Plant and Soil Sciences, University of Delaware, Newark, \\ DE 19717-1303
}

Additional index words. Petroselinum crispum, stand establishment, gibberellic acid

\begin{abstract}
Moss Curled' seeds of parsley (Petroselinum crispum L.) were primed osmotically in polyethylene glycol or matrically in fine, exfoliated vermiculite at $\mathbf{- 0 . 5}$ MPa for 4 or 7 days at 20 or $30{ }^{\circ} \mathrm{C}$ with 0 or $1 \mathrm{~mm} \mathrm{GA}_{3}$. All priming treatments stimulated and hastened germination. Matric priming resulted in greater germination $(89 \%)$ than osmotic priming $(83 \%)$ when seeds were primed for 7 days at $30^{\circ} \mathrm{C}$, but priming agent had no effect on germination percentage following priming at $20^{\circ} \mathrm{C}$ or for 4 days. In seeds primed for 4 days at 20 or $30{ }^{\circ} \mathrm{C}$, matric priming hastened germination more than did osmotic priming. Germination was generally less synchronous with matric than with osmotic priming. Increasing priming time from 4 to 7 days increased the rate of germination, but increased germination synchrony only when seeds were primed at $20{ }^{\circ} \mathrm{C}$. Inclusion of $1 \mathrm{mM} \mathrm{GA}_{3}$ during priming had little or no effect on germination. All matric priming treatments (other than 4-day priming) were repeated to assess seedling emergence in a greenhouse $\left(25^{\circ} \mathrm{C}\right.$ day $/ 22^{\circ} \mathrm{C}$ night $)$. Priming increased the percentage, rate and synchrony of emergence, and increased hypocotyl length at 3 weeks after planting. Priming at $30{ }^{\circ} \mathrm{C}$ with $1 \mathrm{mMGA}_{3}$ resulted in the greatest emergence percentage, hypocotyl length, and shoot dry weight. We conclude that matric priming is a satisfactory alternative to osmotic priming of parsley seeds. Chemical name used: gibberellic acid $\left(\mathbf{G A}_{3}\right)$.
\end{abstract}

Poor field stand establishment in commercial parsley production has led to increased seeding rates in recent years (Dhillon and Latimer, 1986). Parsley germination is slow and asynchronous, with 10 and $28 \mathrm{~d}$ being allowed for the first and last germination counts, respectively (International Seed Testing Association, 1985).

Osmotic priming is the immersion of seeds in solutions of inorganic salts or polyethylene glycol (PEG) of sufficiently low water potential to permit hydration but prevent radicle protrusion. Ely and Heydecker (1981) reported that priming parsley in $-1.2 \mathrm{MPa}$ PEG for 3 weeks at $15{ }^{\circ} \mathrm{C}$ gave greater, earlier, more synchronous emergence, but that washing the seed for $24 \mathrm{~h}$ in continuously running water before priming was of no additional benefit. Pill (1986) noted that this same priming treat-

Received for publication 7 Sept. 1999. Accepted for publication 22 Dec. 1999. Published as miscellaneous paper 1962 of the Delaware Agricultural Experiment Station, Contribution 345 of the Dept. of Plant and Soil Sciences. Mention of trade names in this publication does not imply endorsement by the Delaware Agricultural Experiment Station of products named, nor criticism of similar ones not named. The cost of publishing this paper was defrayed in part by the payment of page charges. Under postal regulations, this paper therefore must hereby be marked advertisement solely to indicate this fact. ${ }^{1}$ Professor. To whom reprint requests should be addressed. E-mail address: wgpill@udel.edu ${ }^{2}$ Undergraduate Student. ment gave earlier emergence and greater seedling shoot weights of 'Forest Green' parsley, but had no effect on percentage of emergence. Additionally, a daily change of the priming solution provided no benefit. Hassell and Kretchman (1987) found that washing parsley seeds in water for $3 \mathrm{~d}$ was as effective in increasing yields as was priming them in PEG $\left(-1.2 \mathrm{MPa}, 15^{\circ} \mathrm{C}\right)$ for 3 weeks. Providing a 3 $\mathrm{d}$ wash before priming parsley seeds in PEG $\left(-0.5 \mathrm{MPa}\right.$ at $25^{\circ} \mathrm{C}$ for $3 \mathrm{~d}$, then $-0.8 \mathrm{MPa}$ for $1.5 \mathrm{~d}$ ) hastened germination but had no effect on germination synchrony or percentage (Akers et al., 1987), but Rabin et al. (1988) noted that this treatment increased parsley stand and yields in cool soil.

Matric priming, in which the low water potential external to the seed is derived from water sorption on matric surfaces, has increased rate and percentage of emergence, and seedling shoot weights in several vegetable crops (Khan et al., 1990). Matric priming of seeds of celery (Apium graveolens L.) and carrot (Daucus carota L.), was more effective than osmotic priming in increasing the rate of emergence and shoot weight, but the effect on emergence was observed only in carrot. Inclusion of gibberellic acid (1 $\left.\mathrm{mm} \mathrm{GA}_{3}\right)$ during matric priming of celery seed had no effect on rate or percentage of emergence, but extending the priming duration from 4 to $7 \mathrm{~d}$ was beneficial. Pill and Finch-Savage (1988) reported that inclusion of a gibberellin analog \{phthalimide [1-(3-chlorophthalimido)- cyclohexanecarboxamide] $\}$ in the PEG solution enhanced the benefits of priming carrot seeds (more rapid and synchronous germination).

The purpose of this work was to compare matric and osmotic priming, with and without $\mathrm{GA}_{3}$ during priming, on parsley germination and seedling emergence.

\section{Materials and Methods}

Germination. Seeds of 'Moss Curled' parsley (Carolina Seeds, Boone, N.C.) were selected to include only single mericarps. The seeds were primed either osmotically in PEG 8000 or matrically in Grade 5 exfoliated vermiculite (W.R. Grace, Cambridge, Mass.) at $-0.5 \mathrm{MPa}$ at 20 or $30^{\circ} \mathrm{C}$ for 4 or $7 \mathrm{~d}$. Seeds were osmotically primed in lidded $125 \times 80 \times$ 20 -mm transparent polystyrene boxes containing two layers of germination paper (Seed Germination Blotters No. 385; Seedburo Co., Chicago) moistened to saturation with PEG solution. The osmotic potential of $-0.5 \mathrm{MPa}$ was achieved with 192 or $212 \mathrm{~g} \cdot \mathrm{L}^{-1}$ of PEG at 20 or $30^{\circ} \mathrm{C}$, respectively (Michel, 1983). For treatments in which $\mathrm{GA}_{3}$ was included during priming, a 1-mm GA 3 solution (ProGibb Plus 2X; Abbott Laboratories, Chicago) was substituted for water in preparation of the PEG solutions.

Seeds were matrically primed in vermiculite $(1 \mathrm{~g}$ seed to $5 \mathrm{~g}$ vermiculite; total weight $1068 \mathrm{mg}$ per cup) in 33-mL plastic souffle cups (Solo Cup Co., Urbana, Ill.). An equal weight of water or $1 \mathrm{mM} \mathrm{GA}_{3}$ solution was added to the vermiculite, which represented $-0.5 \mathrm{MPa}$ according to the moisture characteristic curve established by Khan et al. (1990). The small seed : vermiculite ratio was selected to minimize the reduction in matric potential of the vermiculite during priming. The seeds, liquid, and vermiculite were mixed thoroughly by stirring. Aluminum foil was secured over the tops of the cups to minimize evaporative loss. Priming treatments were scheduled so that all germination tests started at the same time.

Both matrically and osmotically primed seeds were transferred from the boxes or cups to a sieve and the seeds were rinsed for $2 \mathrm{~min}$ to remove adhering PEG or vermiculite. Seeds then were allowed to air-dry for 1 week $\left[21^{\circ} \mathrm{C}\right.$, $40 \%$ relative humidity $(\mathrm{RH})]$ until prepriming weights were reached. Seeds also were soaked in water or $1 \mathrm{mM} \mathrm{GA}_{3}$ for $24 \mathrm{~h}$ at $25^{\circ} \mathrm{C}$ by placing them on saturated double layers of germination paper contained in polystyrene boxes. These soaked seeds were rinsed for 2 min in running water, then allowed to dry for 1 week.

The primed, soaked, and control seeds were transferred to $125 \times 80 \times 20$-mm boxes with two layers of germination paper saturated with half-strength Hoagland solution (Hoagland and Arnon, 1950) to simulate a typical soil ionic strength. The four replications (100 seeds per box) were arranged as a randomized complete block in darkness in an incubator at $20^{\circ} \mathrm{C}$. The numbers of seeds germinated (having visible radicles) were recorded daily until no further germination occurred. Germinated seeds were 
discarded. From these data, the angular transformation of the final germination percentage (FGP), days to $50 \% \mathrm{FGP}\left(\mathrm{G}_{50}\right.$, an inverse measure of germination rate) and days between $10 \%$ and $90 \%$ FGP $\left(\mathrm{G}_{10-90}\right.$, an inverse measure of germination synchrony), were calculated and subjected to analysis of variance (ANOVA).

Seedling emergence and growth. Seeds were matrically primed as described above, except that priming was for $7 \mathrm{~d}$ only. After drying for 1 week, seeds from the four priming treatments (factorial combinations of 20 or $30^{\circ} \mathrm{C}$ and 0 or $1 \mathrm{~mm} \mathrm{GA}_{3}$ ) and nonprimed seeds were sown in peat-lite medium (ProMix BX; Premier Brands, New Rochelle, N.Y.) contained in $17 \times 12 \times 6-\mathrm{cm}$ plastic flats. Each treatment (flat) consisted of 100 seeds sown in four furrows $1 \mathrm{~cm}$ deep and 12 $\mathrm{cm}$ long. The seeded furrows were covered with $1 \mathrm{~cm}$ of peat-lite and the packs were surface irrigated. The experiment, arranged in a randomized complete-block design with four replications, was conducted in a greenhouse with average $25{ }^{\circ} \mathrm{C}$ day $/ 22{ }^{\circ} \mathrm{C}$ night under natural light (May 1999).

The numbers of seedlings emerged (hypocotyl arch visible) were recorded daily until no further emergence occurred. From these data, final emergence percentage of seedlings (FEP) and its angular transformation, days to $50 \%$ FEP ( $\mathrm{E}_{50}$, an inverse measure of emergence rate), days between $10 \%$ and $90 \%$ FEP $\left(\mathrm{E}_{10-90}\right.$, an inverse measure of emergence synchrony), were calculated and subjected to ANOVA. All shoots were cut just below the peat-lite surface 3 weeks after planting. Hypocotyl lengths of a random sample of 25 shoots from each pack were measured. These and the remaining shoots from each pack were dried for 2 weeks at $65{ }^{\circ} \mathrm{C}$. Data for hypocotyl length and shoot dry weight were subjected to ANOVA.

\section{Results and Discussion}

Germination. Seeds of all priming treatments had a greater percentage of and rate of germination than did nonprimed seeds (Table 1). Priming of parsley seeds has increased germination rate (Akers et al., 1987; Ely and Heydecker, 1981) but not germination percentage, except when seeds were germinated under water stress (Akers et al., 1987). Matric priming increased germination (89\%) more than did osmotic priming $(83 \%)$ when seeds were primed for $7 \mathrm{~d}$ at $30^{\circ} \mathrm{C}$. Priming agent had no effect on germination percentage when seeds were primed for $4 \mathrm{~d}$ or at $20^{\circ} \mathrm{C}$. Matric priming induced faster germination than did osmotic priming for seeds primed for $4 \mathrm{~d}$ at 20 or $30^{\circ} \mathrm{C}$. Increasing priming time from 4 to $7 \mathrm{~d}$ increased germination rate at both temperatures. Osmotic priming generally resulted in greater germination synchrony than did matric priming. Prolonging priming from 4 to $7 \mathrm{~d}$ generally increased germination synchrony only when seeds were primed at $20^{\circ} \mathrm{C}$, so that the $\mathrm{G}_{10-90}$ values of these seeds were 1.8 to $3.0 \mathrm{~d}$ less than those of nonprimed seeds. We know of no other report showing similar benefits to germination percentage and rate provided by matric and osmotic priming of parsley seeds.

Slow and erratic germination in several species of Apiaceae has been attributed to inhibitory substances in the seed covering (Hassel and Kretchman, 1997) and to embryo immaturity (Gray and Steckel, 1983). The beneficial effect of priming on parsley germination reported here may reflect, at least in part, the leaching of inhibitors. In earlier work, however, daily change of the PEG solution during priming failed to increase percentage of emergence of parsley (Pill, 1986). Hassel and Kretchman (1997) observed that aqueous leachate from parsley seeds inhibited radish seed germination, and leachate from primary umbels caused less inhibition than that from secondary or tertiary umbels. Kato et al. (1978) identified coumarin (heraclenol) as a germination-inhibiting substance in parsley seeds.

Although soaking seeds in water or $1 \mathrm{~mm}$ $\mathrm{GA}_{3}$ for $48 \mathrm{~h}$ reduced $\mathrm{G}_{50}$ relative to that of control seeds, FGP decreased and $\mathrm{G}_{10-90}$ was unaffected (Table 1). Thus, rapid seed hydration during soaking reduced seed viability, whereas slower hydration with priming improved the percentage, rate and synchrony of germination.

Table 1. Final germination percentage (FGP) and the angular transformation of FGP, days to $50 \%$ of FGP $\left(\mathrm{G}_{50}\right)$, and days between $10 \%$ and $90 \%$ of FGP $\left(\mathrm{G}_{10-90}\right)$ of 'Moss Curled' parsley seeds following osmotic or matric priming.

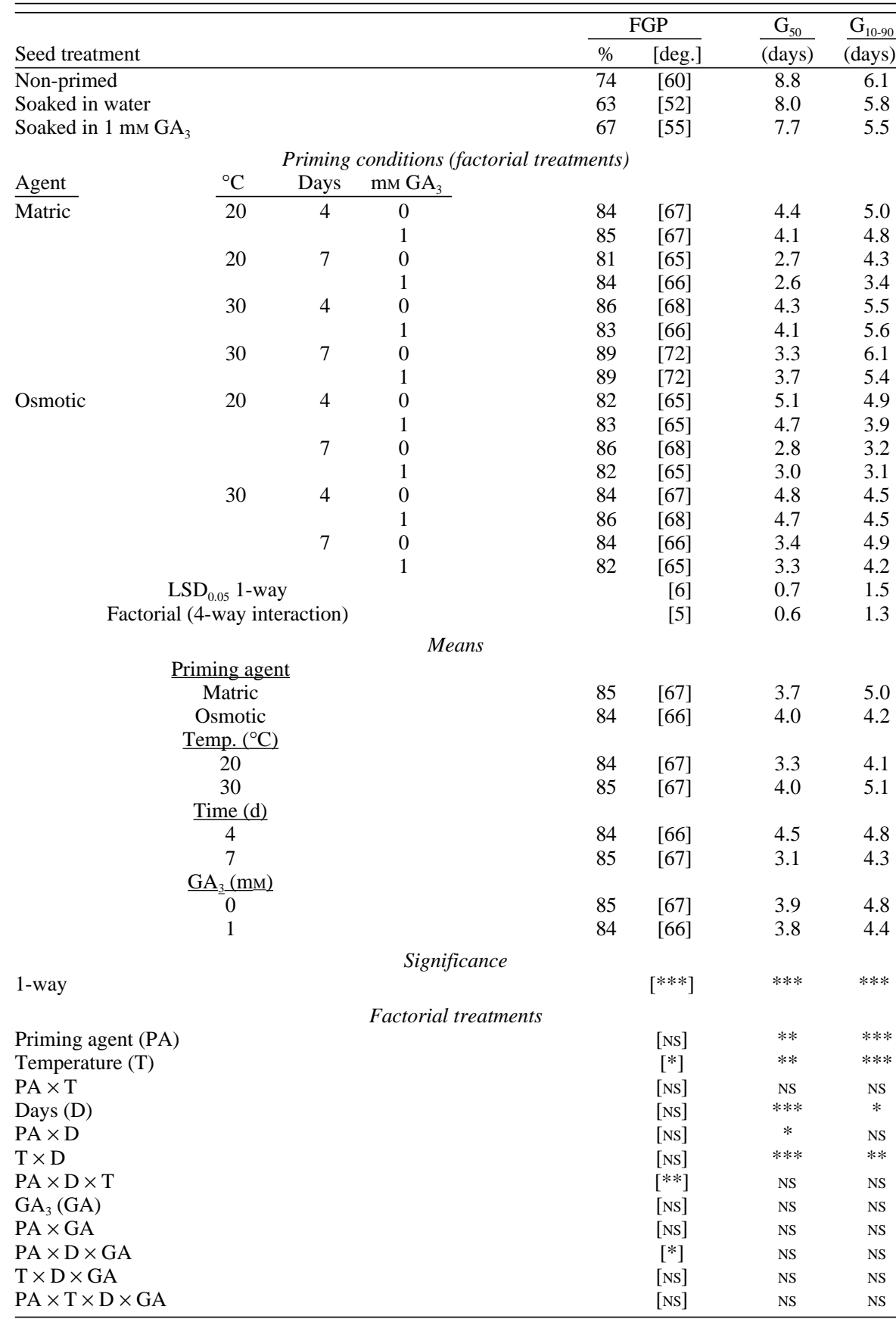


Table 2. Final emergence percentage (FEP) and its angular transformation, days to $50 \%$ of FEP ( $\left.\mathrm{E}_{50}\right)$, days between $10 \%$ and $90 \%$ of FEP $\left(\mathrm{E}_{10-90}\right)$, hypocotyl length, and shoot dry weight 3 weeks after planting matrically primed or nonprimed seeds of 'Moss Curled' parsley.

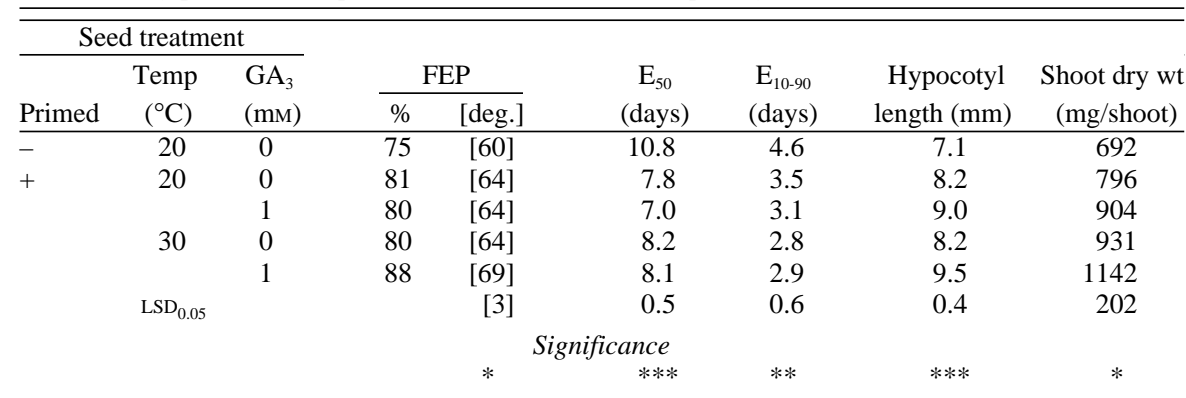

,*** Significant at $P \leq 0.05,0.01$, or 0.001 .

Increasing priming from 4 to $7 \mathrm{~d}$ decreased $\mathrm{G}_{50}$ (Table 1). Four d of priming in vermiculite reduced $\mathrm{G}_{50}$ more than did priming in PEG, but $\mathrm{G}_{50}$ values were similar after $7 \mathrm{~d}$ of priming. Ely and Heydecker (1981) noted that each successive week (1 to 3 ) of priming parsley seeds at $15^{\circ} \mathrm{C}$ increased the germination rate. Akers et al. (1987) showed, however, that priming in warm, aerated PEG for a shorter period $\left(4.5 \mathrm{~d}\right.$ at $\left.25^{\circ} \mathrm{C}\right)$ likewise increased the rate of parsley seed germination.

Germination asynchrony averaged $0.8 \mathrm{~d}$ greater for matrically primed than for osmotically primed seeds (Table 1). While increasing priming from 4 to $7 \mathrm{~d}$ at $20^{\circ} \mathrm{C}$ increased germination synchrony, no such response occurred following priming at $30{ }^{\circ} \mathrm{C}$. The $\mathrm{G}_{10-90}$ of seeds primed for $4 \mathrm{~d}$ at $20^{\circ} \mathrm{C}$ was $43 \%$ lower than that of nonprimed seeds. Inclusion of $\mathrm{GA}_{3}$ during priming had no effect on germination synchrony. Others (Akers et al., 1987; Ely and Heydecker, 1981) have reported no effects of priming on germination synchrony of parsley seed. Gray and Steckel (1983) showed that priming of carrot seeds increased both embryo length and the variability of embryo length. If such responses occur during parsley seed priming, treatments that hasten germination or emergence would not be expected to improve emergence synchrony.

Inclusion of $\mathrm{GA}_{3}$ during parsley seed priming had little effect on seed germination (Table 1). Similarly, Khan et al. (1990) found that $1 \mathrm{mM} \mathrm{GA}_{3}$ during celery priming had no effect on emergence parameters, but did increase shoot fresh weight.

Seedling emergence and growth. Following all priming treatments, seeds had higher FEP, lower $\mathrm{E}_{5,0}$ and lower $\mathrm{E}_{10-90}$ than did nonprimed seeds (Table 2). Matric priming for $7 \mathrm{~d}$ at $30^{\circ} \mathrm{C}$ in $1 \mathrm{~mm} \mathrm{GA}_{3}$ increased emergence $(88 \%)$ more than did the other priming treatments $(80 \%)$. $\mathrm{GA}_{3}$ inclusion during priming at $30^{\circ} \mathrm{C}$ had no effect on emergence rate, but its inclusion during priming at $20^{\circ} \mathrm{C}$ reduced $\mathrm{E}_{50}$ by $0.8 \mathrm{~d}$. Priming treatments had little effect ( $0.7 \mathrm{~d}$ range) on synchrony of emergence.

Priming stimulated hypocotyl length at 3 weeks after planting, with $1 \mathrm{~mm} \mathrm{GA}$ during priming increasing the length by an average 1 mm (Table 2). Priming at $30^{\circ} \mathrm{C}$ with $1 \mathrm{~mm} \mathrm{GA}_{3}$ stimulated hypocotyl length and shoot dry weight more than did other priming treatments. Hypocotyls were $25 \%$ longer and shoots were $65 \%$ heavier than those from nonprimed seeds.

Greater seedling shoot weights from primed than from nonprimed parsley seeds have been reported (Ely and Heydecker, 1981; Pill, 1986). Such increased seedling growth probably should be attributed to more rapid seedling emergence, rather than to increased relative growth rate, as observed in leek (Allium porrum L.) (Brocklehurst et al., 1984) and Kentucky bluegrass (Poapratensis L.) (Pill and Korengel, 1997). The positive effect on seedling growth of $\mathrm{GA}_{3}$ during priming at $30^{\circ} \mathrm{C}$ can result from stimulated growth of hypocotyls (Khan et al., 1992) or of leaf petioles and laminas (Pill and Haynes, 1996). Since priming parsley seeds increased final plant fresh weights (Ely and Heydecker, 1981), initial advantages in emergence rate due to seed priming can be maintained. However, field conditions can modify the response of primed seeds. For instance, priming parsley seeds increased plant stand and final yield in an earlier (cool) field planting, but not in later plantings (Rabin et al., 1988).

We conclude that matric priming is a satisfactory alternative to osmotic priming of parsley seed. Matric priming at $30{ }^{\circ} \mathrm{C}$ for 1 week in $1 \mathrm{mM} \mathrm{GA}_{3}$ increased emergence from $75 \%$ to $88 \%$ and increased seedling shoot dry weight by $65 \%$.

\section{Literature Cited}

Akers, S.W., G.A. Berkowitz, and J. Rabin. 1987. Germination of parsley seed primed in aerated solutions of polyethylene glycol. HortScience 22:250-252.

Brocklehurst, P.A., J. Dearman, and R.L.K. Drew. 1984. Effects of osmotic priming on seed germination and seedling growth in leek. Scientia Hort. 24:201-210.

Dhillon, P.S. and R.G. Latimer. 1986. Costs of producing fresh market vegetables in southern New Jersey. New Jersey Agr. Expt. Sta. Bul.P-021231.

Ely, P.R. and W. Heydecker. 1981. Fast germination of parsley seeds. Scientia Hort. 15:127-136.

Gray, D. and J.R.A. Steckel. 1983. Seed quality in carrots: The effects of seed crop plant density, harvest date and seed grading on seed and seedling variability. J. Hort. Sci. 58:393-401.

Hassell, R.L. and D.W. Kretchman. 1987. Improving parsley stands through seed priming and improved cultural practices. Acta Hort. 198:59-63.

Hassell, R.L. and D.W. Kretchman. 1997. The effects of umbel order, soaking, and scarification on germination inhibiting substances in Petroselinum crispum L. and other Apiaceae seeds. HortScience 32:1227-1230.

Hoagland, D.R. and D.I. Arnon. 1950. Water culture method for growing plants without soil. California Agr. Expt. Sta. Circ. 47.

International Seed Testing Association. 1985. International rules for seed testing. Seed Sci. Technol. 13:299-355.

Kato, T., M. Kobayashi, N. Sasaki, Y. Kitahara, and N. Takahashi. 1978. The coumarin hereclenol as a growth inhibitor in parsley seeds. Phytochemistry $17: 158-159$.

Khan, A.A., J.D. Maguire, G.S. Abawi, and S. Ilyas. 1992. Matriconditioning of vegetable seeds to improve stand establishment in early field plantings. J. Amer. Soc. Hort. Sci. 117:41-47.

Khan, A.A., H. Miura, J. Prusinski, and S. Ilyas. 1990. Matriconditioning of seeds to improve emergence, p. 19-40. In: Natl. Symp. on Stand Establishment for Hort. Crops (Univ. of Minnesota).

Michel, B.E. 1983. Evaluation of the water potentials of solutions of polyethylene glycol 8000 both in the presence and absence of other solutes. Plant Physiol. 72:66-70.

Pill, W.G. 1986. Parsley emergence and seedling growth from raw, osmoconditioned and pregerminated seeds. HortScience 21:11341136.

Pill, W.G. and J.G. Haynes. 1996. Gibberellic acid during priming of Echinacea purpurea (L.) Moench seeds improves performance after seed storage. J. Hort. Sci. 71:287-295.

Pill, W.G. and T.K. Korengel. 1997. Seed priming advances the germination of Kentucky bluegrass (Poapratensis L.). J. Turfgrass Mgt. 2:2743.

Pill, W.G. and W.E. Finch-Savage. 1988. Effects of combining priming and plant growth regulator treatments on the synchronisation of carrot seed germination. Ann. Appl. Biol. 113:383-389.

Rabin, J., G.A. Berkowitz, and S.W. Akers. 1988. Field performance of osmotically primed parsley seed. HortScience 23:554-555. 